\title{
Development, reliability and validity of the Safe Use of Mobility Aids Checklist (SUMAC) for 4-wheeled walker use in people living with dementia
}

\author{
Susan W. Hunter ${ }^{1 *}$ (D) Alison Divine ${ }^{2}$, Humberto Omana ${ }^{3}$, Ed Madou $^{1}$ and Jeffrey Holmes ${ }^{4}$
}

\begin{abstract}
Background: Balance and gait problems are common and progressive in dementia. Use of a mobility aid provides physical support and confidence. Yet, mobility aid use in people with dementia increases falls three-fold. An assessment tool of mobility aid safety in people with dementia does not currently exist. The objectives of this study were: 1) to develop a tool for the evaluation of physical function and safe use of a 4-wheeled walker in people with dementia, and 2) to evaluate its construct and criterion validity, inter-rater and test-retest reliability and minimal detectable change.

Methods: Healthcare professionals (HCP) experienced in rehabilitation of people with dementia participated in focus groups for item generation of the new tool, The Safe Use of Mobility Aid Checklist (SUMAC). The SUMAC evaluates physical function (PF) and safe use of the equipment (EQ) on nine tasks of daily life. Reliability was evaluated by HCP $(n=5)$ scored participant videos of people with dementia $(n=10)$ using a 4-wheeled walker performing the SUMAC. Inter-rater and test-retest reliability was assessed using intra-class correlation coefficients (ICC). Construct validity evaluated scores of the HCPs to a consensus HCP panel using Spearman's rank-order correlations. Criterion validity evaluated SUMAC-PF to the Performance-Oriented Mobility Assessment (POMA) gait subscale using Spearman's rank-order correlations.

Results: Three focus groups $(n=17)$ generated a tool comprised of nine tasks and the components within each task for physical function and safe use. Inter-rater reliability was statistically significant for SUMAC-PF (ICC $=0.92$, $95 \% \mathrm{Cl}(0.81,0.98), p<0.001)$ and SUMAC-EQ. $(\mathrm{ICC}=0.82,95 \% \mathrm{Cl}(0.54,0.95), p<0.001)$. Test-retest reliability was statistically significant for SUMAC-PF (ICC $=0.89,95 \% \mathrm{Cl}(0.81,0.94), p<0.001)$ and SUMAC-EQ. (ICC $=0.88,95 \% \mathrm{Cl}$ $(0.79,0.93), p<0.001)$. As hypothesized, the POMA gait subscale correlated strongly with the SUMAC-PF $\left(r_{s}=0.84\right)$, but not EQ $\left(r_{s}=0.39\right)$.

\footnotetext{
* Correspondence: susan.hunter@uwo.ca

${ }^{1}$ School of Physical Therapy, University of Western Ontario, Room 1588, Elborn College, London, ON N6G 1H1, Canada

Full list of author information is available at the end of the article
}

(c) The Author(s). 2020 Open Access This article is licensed under a Creative Commons Attribution 4.0 International License, which permits use, sharing, adaptation, distribution and reproduction in any medium or format, as long as you give appropriate credit to the original author(s) and the source, provide a link to the Creative Commons licence, and indicate if changes were made. The images or other third party material in this article are included in the article's Creative Commons licence, unless indicated otherwise in a credit line to the material. If material is not included in the article's Creative Commons licence and your intended use is not permitted by statutory regulation or exceeds the permitted use, you will need to obtain permission directly from the copyright holder. To view a copy of this licence, visit http://creativecommons.org/licenses/by/4.0/. The Creative Commons Public Domain Dedication waiver (http://creativecommons.org/publicdomain/zero/1.0/) applies to the data made available in this article, unless otherwise stated in a credit line to the data. 
(Continued from previous page)

Conclusions: The focus groups and research team developed a tool of nine tasks with evaluation on physical function and safe use of a 4-wheeled walker for people with dementia. The SUMAC tool has demonstrated content validity for the whole scale and good construct and criterion validity for the SUMAC-PF and SUMAC-EQ. The subscores of the SUMAC demonstrated excellent to good inter-rater and test-retest reliability.

Keywords: Dementia, Walkers, Geriatric assessment, Reliability, Validity

\section{Background}

People with dementia have an annual falls risk of 60$80 \%$, twice that of their cognitively healthy aged peers [1], and have a higher risk of major fall-related injuries, such as hip fractures [2]. Falls in people with dementia are multifactorial, including orthostatic syncope from disease-related changes in autonomic function, prescription medications, vision problems, functional status and the severity of the disease $[3,4]$. Among adults with dementia, balance problems and gait disorders are common and progressive $[5,6]$. These balance and gait problems are associated with an increased risk of falls in people with dementia $[4,7]$. The provision of a mobility aid (e.g., cane or walker) can be an important treatment option to compensate for balance and gait impairments [8] as mobility is fundamental to successful aging and quality of life in older adults [9].

Use of a mobility aid has been found to improve walking stability $[8,10]$ and allow greater ambulation and social participation in cognitively healthy older adults [11]. Yet, use of a mobility aid in people with dementia has been found to be independently associated with a threefold increased odds of falling [4]. This finding has serious implications for long-term care facilities as $79 \%$ of residents have cognitive impairment, $70 \%$ use a 4wheeled walker and $80 \%$ fall each year $[9,12,13]$.

The increased risk of falls with use of a mobility aid is multifactorial, factors include uncompensated physical deficits, increased cognitive demands, and cognitive deficits related to insight and memory [4, 14-16]. Use of a mobility aid is a complex motor activity requiring motor sequencing and coordination, navigating and selecting a path through in the environment, along with remembering strategies for use (e.g., use of the brakes). The transition to use of a mobility aid is an important milestone for people with dementia as it can occur when brain function may be challenged to accommodate greater resource utilization required to use the mobility aid [15, 16]. Additionally, cognitive impairments may compromise learning of new tasks resulting in unsafe practices when using the equipment [8].

The majority of older adults obtain a mobility aid without consulting a healthcare professional $[17,18]$. In addition, there are accessibility issues for people using 4wheeled walkers. Lindemann et al. identified obstacle clearance and opening a door against the direction of walking as the biggest problem for older adults using a 4-wheeled walker [19]. In the absence of professional input, the mobility aid may not appropriately compensate for deficits in balance and gait, and the person with dementia will not receive training on safe use of the equipment. Research by Hunter et al. [20] found that caregivers of people with dementia were the key people to identify the need for a mobility aid, obtained the mobility aid, and provided ongoing reminders for its use in daily activities to the person with dementia.

Rehabilitation can improve the functional mobility of people with dementia through gains in strength, balance and endurance [21]. Yet access to rehabilitation is not guaranteed and even those who do receive services may have ongoing deficits after completion of an exercise program. Therefore, prescription of mobility aids is still an important clinical tool to compensate for deficits. People with dementia newly learning or experienced in using a 4-wheeled walker demonstrate increased cognitive demands and a deterioration in gait in distracting situations and when manoeuvring around obstacles [15, 22]. Additionally, the uptake and safe use of mobility aids may be impacted by cognitive impairment through a lack of self-awareness or incomplete learning to use the equipment safely [8]. The appropriate use of mobility aids is important for falls prevention, yet incorrect equipment use is common in older adults [23]. Fall prevention strategies that are successful in older adults without cognitive problems have not been successful in reducing fall risk in people with dementia. As a result of insufficient evidence, the most prominent fall prevention guidelines do not provide any recommendations for people with cognitive impairment [24].

Currently, there is no standardized assessment scale to evaluate function and the safe use of a 4-wheeled walker. A standardized scale would facilitate reporting among healthcare professionals, care planning to optimize client safety and targeted interventions to lessen falls risk. Additionally, it is important for delivery of care to monitor change in function over time as a consequence of progression of cognitive deficits or participation in rehabilitation. Therefore, the objectives of this study were: 1) to develop a tool for the evaluation of physical function and safety with use of a 4-wheeled walker in people 
with dementia, and 2) to evaluate its construct and criterion validity, inter-rater and test-retest reliability and minimal detectable change.

\section{Methods}

This project involved two phases: Phase 1 was the item generation and development of the assessment scale (cross-sectional design) and Phase 2 was a reliability and validation study for the scale developed in Phase 1 (cross-sectional design).

\section{Phase 1: item generation and development}

Items were generated from two sources for content validity: i) the research team and ii) healthcare professionals. The research team $(\mathrm{SWH}, \mathrm{AD}, \mathrm{JH})$ generated items from reviewing existing mobility scales, discussion with experts in mobility among people with dementia and a search of healthcare textbooks on clinical skills for mobility aid training. We also conducted two focus groups of healthcare professionals from relevant disciplines in London, Ontario Canada providing care across health settings for people with dementia $(n=12$; 1 geriatrician, 2 registered nurses, 5 physical therapists and 4 occupational therapists). The healthcare professionals were working in the areas of acute hospital care, community care, long-term care, day hospital and rehabilitation hospital. Eleven (92\%) participants had 10 or more years of total clinical experience working in geriatrics. All healthcare professionals provided written informed consent prior to the start of data collection.

Our focus groups identified the 4-wheeled walker as the most common mobility aid used in this patient population. Therefore, items were sought that represented 1) the minimum functional tasks needed to assess and evaluate independence and safety with the use of a 4-wheeled walker, and 2) the components within each task that can be objectively evaluated with respect to function and safe use.

The focus groups and work by the research team generated 11 tasks and components within each task. To render the scale manageable in the clinical and research setting, the authors sought to reduce the number of items. The information was presented to an independent panel of five healthcare professionals (1 registered nurse, 2 physical therapist, and 2 occupational therapists) with more than 10 years of clinical experience in geriatrics and who had not participated in the first set of focus groups. The participants were asked, "Rank how important it is to include each task, regardless of setting, when assessing physical function and safety with a 4-wheeled walker". The 11 identified tasks were ranked on a 5point Likert scale with a score of 1 representing "least important" and 5 representing "most important". The scores for each task were summed and averaged across raters. Tasks were kept if the average score was rated $\geq 4$, indicative of the item being rated as either important or most important (Table 1).

The evaluation resulted in a final selection of nine tasks with task components that comprise The Safe Use of Mobility Aids Checklist (SUMAC). The research team categorized the components in each task into two separate areas of focus, physical function (PF) which includes items related to an individual's physical ability to perform the task (e.g., stand independently) and use of the equipment (EQ) which includes items related to an individual's safety in using their 4-wheeled walker (e.g., brakes engaged on walker). Items for PF and $\mathrm{EQ}$ are not equally present across the tasks and reflect to some extent the difficulty of the activity. The distribution of scoring items for each task (number of PF items:number of EQ items) are: sit to stand (3:7); pivot turn to sit in chair (3:7); walking on level surface (11:6); walking with horizontal head turns (1:6); walking with concurrent cognitive task (1:6); walking around obstacles - figure of eight (1:6); walk through an open doorway (1:5); open, walk through and close door that opens away from the person (1:10); and open, walk through and close door that opens in to person (1:10). Physical function items are rated on a 3 -point scale $(0,1,2)$ and use of equipment is a dichotomous scale, where the item is scored as observed yes (1) or no (0). Total PF scores can range from 0 to 40 and the total EQ score can range from 0 to 63. A higher score in each category indicates better physical function and safety. (The full scale is available in the Supplementary File 1 and at www.mobility-inaging-lab.ca).

\section{Phase 2: reliability and validity evaluation}

This phase of the study involved the recruitment of people living with dementia and a separate sample of health care professionals. The project was conducted in accordance to the Declaration of Helsinki and was approved by the University of Western Ontario Research Ethics Board for Health Sciences Research Involving Human Subjects.

People with dementia who used a 4-wheeled walker for ambulation were recruited from a local day program to be evaluated with the SUMAC. Participants had a diagnosis of probable AD from a geriatrician based on the National Institute of Neurologic and Communicative Disorders and Stroke-AD and Related Disorders Association (NINCDS-ARDRA) criteria [25]. Inclusion criteria were: 50 years of age and older, English proficiency, able to follow instructions, mild to moderate disease severity, able to walk $60 \mathrm{~m}$ without support from another person and have a substitute decision maker (in all cases a family member of the person with dementia) to provide information about health and daily activities. Exclusion 
Table 1 Results of ranking tasks generated in focus groups to be considered part of a minimum set of tasks that every person should complete, regardless of living setting, when assessing physical function and safety with a 4-wheeled walker

\begin{tabular}{lll}
\hline Task & \multicolumn{2}{l}{ Scores on 5-point Likert scale } \\
\cline { 2 - 3 } & Median Score & Range of Scores \\
\hline Sit to stand & 5 & $3-5$ \\
Pivot turn and sit in a chair & 5 & $4-5$ \\
Walking on a level surface & 5 & $3-5$ \\
Walking with horizontal head turns & 4.5 & $3-5$ \\
Walking with concurrent cognitive task & 4 & $4-5$ \\
Walking around obstacles (figure of 8) & 5 & All scored at 5 \\
Walking up a ramp & 3 & $2-5$ \\
Walking down a ramp & 3 & $2-5$ \\
Walking through an open doorway & 5 & $1-5$ \\
Open, walk through and close door that opens away & 4 & $2-5$ \\
Open, walk through and close door that opens in & 4 & $2-5$ \\
\hline
\end{tabular}

5-point Likert scale with a score of 1 representing "least important" and 5 representing "most important"

criteria were any muscle and/or nerve problem that limited movement. Informed written consent was provided by either the participant or their substitute decision maker and then the participant provided assent to participate in the study.

Demographic and clinical information collected on the participants included age, gender, falls in the previous 12 months, number of prescription medications, number of comorbidities and instrumental activities of daily living, as per the Lawton-Brody Instrumental Activities of Daily Living and Basic Activities of Daily Living scales [26]. Participants also completed the IconographicalFalls Efficacy Scale, which has been validated in older adults with cognitive impairment [27]. Participants $(n=$ 10) were videotaped while performing the nine tasks of the SUMAC.

The raters were a convenience sample of five healthcare professionals (5 physiotherapists). All healthcare professionals provided written informed consent prior to the start of data collection. The healthcare professionals were working in the areas of acute hospital care, community care, and long-term care. Two people $(40 \%)$ had 10 or more years of total clinical experience working in geriatrics. The inclusion criterion was: registered healthcare professional with experience working with older adults with dementia. Each assessor attended a one-hour one-on-one training session on the use of the SUMAC. In the training session, each person was presented with a description of the development of the tool and the rationale for its creation, received a copy of the assessment tool and was given a detailed instruction of the components and items within the tool. The last activity in the training session was evaluating videos of a person performing the nine tasks of the SUMAC.

\section{Reliability}

In the reliability evaluation, each of the healthcare professionals was asked to view each participant's video and evaluate them using the SUMAC on two occasions. The two visits were set 1 week apart. In both visits the viewing order of each participant's video was randomized, but all components of the SUMAC were presented together and in the order in the tool for each participant.

\section{Validity}

The evaluation of construct validity was performed by a panel of eight healthcare professionals with clinical experience working with older adults and people with dementia (6 physical therapists, 2 registered kinesiologists) who had not participated in any aspect of the development or reliability evaluations of the SUMAC. All members of the panel had the same training session used in the reliability study. The panel viewed the participant videos in a group setting in a single session with discussion until consensus was reached in scoring the physical function and safe use of the equipment. The scores of the HCP panel were compared to the scores of the individual $\mathrm{HCP}$ from the reliability study.

Our sample of five HCP who participated in the reliability study of the SUMAC also completed the gait subscale of the Performance-Oriented Mobility Assessment (POMA) gait subscale on each participant. The HCP viewed videos of each participant walking at their selfselected usual gait speed using their 4-wheeled walker over a distance of a $6-\mathrm{m}$. Criterion validity was evaluated by comparing the PF and EQ scores of the SUMAC against the Performance-Oriented Mobility Assessment (POMA) gait subscale scores [28]. The POMA is a reliable tool in people with dementia [29]. 


\section{Data analysis}

\section{Reliability}

Values for relative and absolute reliability were calculated. An a priori sample size calculation $(\alpha=0.05$ and $\beta=0.20$ ) for the reliability study indicated that 10 participants and 5 assessors making 2 evaluations would be needed if a target ICC of 0.90 was desired [30]. This sample size minimized recruitment and participant burden while optimizing the use of multiple healthcare professionals as assessors of the videos.

The relative reliability values of inter-rater and testretest reliability were calculated for the PF and EQ domain scores of the SUMAC using the intra-class correlation coefficient (ICC). Repeated measurements by different raters on the same day were used to calculate inter-rater reliability, while repeated measurements by the same rater on different days were used to calculate test-retest reliability. The ICC values were categorized to provide a means to quantify the strength of the relationship; therefore an ICC value greater than 0.90 was considered excellent, between 0.80 to 0.89 was good, 0.70 to 0.79 was fair, and values less than 0.70 are considered of questionable clinical value [31].

Two measures of absolute reliability were calculated: standard error of measurement (SEM) and minimal detectible change with a $95 \%$ confidence interval $\left(\mathrm{MDC}_{95}\right)$ for the PF and EQ domain scores of the SUMAC. The SEM is the measurement error associated with a single value and is expressed in the same units as the scale [31]. The smaller the SEM, the greater the absolute reliability. The MDC95 is an estimate of the smallest change in the score that can be detected beyond measurement error [32]. It is also measured in the same units as the measurement scale. For the present study, the SEM was calculated using pooled standard deviation (SD) and ICC values for each group. Calculations of SEM and $\mathrm{MDC}_{95}$ were:

$$
S E M=S D \sqrt{(1-I C C)}, M D C_{95}=S E M \times \sqrt{2} \times 1.96
$$

\section{Validity}

Spearman's rank-order correlations were also used to assess construct validity between each healthcare professional and the separate HCP panel consensus scores. Three scores were compared: each participant's mean score for each of the nine tasks and a total score using the minimum and maximum scores.

Spearman' rank-order correlation analysis was used to evaluate criterion validity between the gait component of the POMA, and the SUMAC-PF and SUMAC-EQ scores. We hypothesized that the POMA score would be moderately correlated with the SUMAC-PF score and not correlated with the SUMCA-EQ score.
To interpret Spearman's correlation coefficients related to the assessment of criterion and construct validity, the following thresholds were used: $\geq 0.50$ was deemed strong, $0.31-0.49$ was moderate to strong, $0.11-$ 0.30 was weak to moderate, and $\leq 0.10$ was considered a non-existent relationship [33]. All statistical analyses were performed using SPSS version 25.0 (IBM Inc., Chicago, IL, USA). Statistical significance was set at $p<0.05$.

\section{Results}

The demographic characteristics of the ten people with dementia who were evaluated in the reliability phase of the study are presented in Table 2 .

\section{Reliability}

The values for the absolute reliability were the following: SEM for the PF was 1.31 and the EQ was 1.93; the $\mathrm{MDC}_{95}$ was 3.62 for PF and 5.35 for EQ. A good to excellent inter-rater reliability was observed for both testing sessions in the PF and EQ domains (Table 3) Additionally, good test-retest reliability was observed for the PF (ICC $=0.89,95 \% \mathrm{CI}(0.81$ to 0.94$), p<0.001)$ and EQ. $\quad(\mathrm{ICC}=0.88, \quad 95 \% \mathrm{CI} \quad(0.79$ to 0.93$), \quad p<0.001)$ domains.

\section{Validity}

In the evaluation of construct validity, moderate to strong positive correlations for the PF score (mean total score: $\mathrm{r}_{\mathrm{s}}=0.92, p<0.001$; minimum score: $\mathrm{r}_{\mathrm{s}}=0.93, p<$ 0.001; maximum score: $\mathrm{r}_{\mathrm{s}}=0.68, p=0.03$ ) and EQ score (mean total score: $\mathrm{r}_{\mathrm{s}}=0.82, p=0.004$; minimum score: $\mathrm{r}_{\mathrm{s}}=0.60, p=0.06 ;$ maximum score: $\mathrm{r}_{\mathrm{s}}=0.90, p=0.03$ ) (Fig. 1a and b).

In the evaluation of criterion validity, a strong positive correlation was observed between the POMA gait scores and PF scores $\left(\mathrm{r}_{\mathrm{s}}=0.84\right.$ ) (Fig. $2 \mathrm{a}$ and $\mathrm{b}$ ). A weak positive correlation was observed between the POMA gait scores and EQ scores $\left(r_{\mathrm{s}}=0.39\right)$.

Table 2 Characteristics of people with dementia who participated in the reliability study for the SUMAC. $(n=10)$

\begin{tabular}{ll}
\hline Variable & Mean \pm SD, or $\mathbf{n}(\%)$ \\
\hline Age (years) & $88.5 \pm 4.2$ \\
Gender, n (\% female) & $6(60.0 \%)$ \\
Instrumental Activities of Daily Living & $0.8 \pm 0.9$ \\
Basic Activities of Daily Living & $3.8 \pm 1.1$ \\
History of Falls in the Past 12 Months, n (\%) & $1(10.0 \%)$ \\
Fear of Falling, n (\%) & $3(30.0 \%)$ \\
Number of Prescription Medications & $7.2 \pm 3.7$ \\
Number of Comorbidities & $2.9 \pm 1.1$ \\
\hline
\end{tabular}

SD Standard deviation 
Table 3 Scores and reliability values for the two components of the SUMAC

\begin{tabular}{|c|c|c|}
\hline & \multicolumn{2}{|c|}{ Component scores of the Safe Use of Mobility Aids Checklist } \\
\hline & Physical Function & Interaction with Equipment \\
\hline \multicolumn{3}{|l|}{ Mean (SD), range } \\
\hline Assessment \#1 & $31.25(3.81), 23-39$ & $44.75(5.40), 28-55$ \\
\hline Assessment \#2 & $29.80(4.10), 18-37$ & $43.46(5.75), 28-53$ \\
\hline \multicolumn{3}{|c|}{ Relative Reliability (Intraclass correlation coefficients $(95 \% \mathrm{Cl}), p$-value) } \\
\hline Assessment \#1: Inter-rater reliability & $0.72(0.31,0.92), p=0.003$ & $0.84(0.61,0.96), p<0.001$ \\
\hline Assessment \#2: Inter-rater reliability & $0.92(0.81,0.98), p<0.001$ & $0.82(0.54,0.95), p<0.001$ \\
\hline Test-retest reliability & $0.89(0.81,0.94), p<0.001$ & $0.88(0.79,0.93), p<0.001$ \\
\hline \multicolumn{3}{|l|}{ Absolute Reliability } \\
\hline Standard Error of Measurement (SEM) & 1.31 & 1.93 \\
\hline Minimum Detectable Change (MDC 95 ) & 3.64 & 5.35 \\
\hline
\end{tabular}

SD Standard deviation, $\mathrm{Cl}$ Confidence interval

\section{Discussion}

This study reports the development and psychometric properties of a new tool for the assessment of physical function and safe use of a 4-wheeled walker for people with dementia. In the scale development phase, content validity of the items in the scale was achieved using input from researchers in the field of geriatrics and focus groups of healthcare professionals with expertise in the care of people with dementia. The research team and focus groups generated an assessment tool comprised of nine tasks. Within each task is a list of items that clinicians would rate for physical function and safe use. The assessment tool, the Safe Use of Mobility Aids Checklist (SUMAC), yields scores in physical function and safe use of the equipment in each task. There was strong support for construct and criterion validity of the SUMAC tool. The SUMAC was determined to have good to excellent inter-rater and test-retest reliability, with an $\mathrm{MDC}_{95}$ of 3.62 for PF and 5.35 for EQ. Overall, the psychometric properties provide support for the use of the scale in clinical practice.
Our focus groups clearly indicated that in their clinical practice 4-wheeled walkers were the most commonly prescribed and used mobility aid for this population. This observation is consistent with reports that the rate of walker use has greatly increased in recent years and that 4-wheeled walkers are the most common prescribed mobility aid for older adults [34]. There is also a strong link between 4-wheeled walker use and fall-related injuries among older adults who use a mobility aid. Stevens et al. [35] found use of walkers was associated with seven times as many injuries compared to use of canes. Van Riel et al. [36] found that most injuries sustained while using a 4-wheeled walker resulted from a fall, $60 \%$ of these injuries were fractures and hip fracture (25\%) was the most common. The three-fold increased odds of falls in people with dementia over the cognitively normal, as well as the former group's higher risk of sustaining major fall-related injuries, warrants standardizing an assessment tool for healthcare professionals to identify physical function and safe use of a 4-wheeled walker.
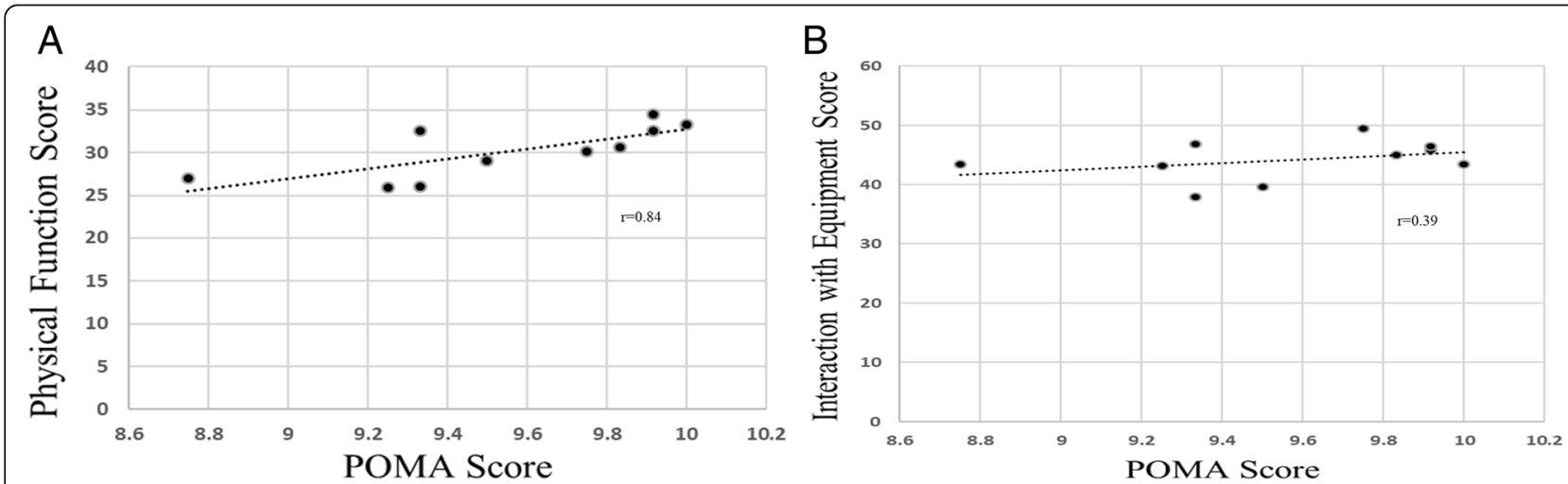

Fig. 1 Construct validity as measured through Spearman's correlation analysis of SUMAC physical performance scores (a) and interaction with equipment scores (b) to scores of the Performance-Oriented Mobility Assessment (POMA) among healthcare practitioners 

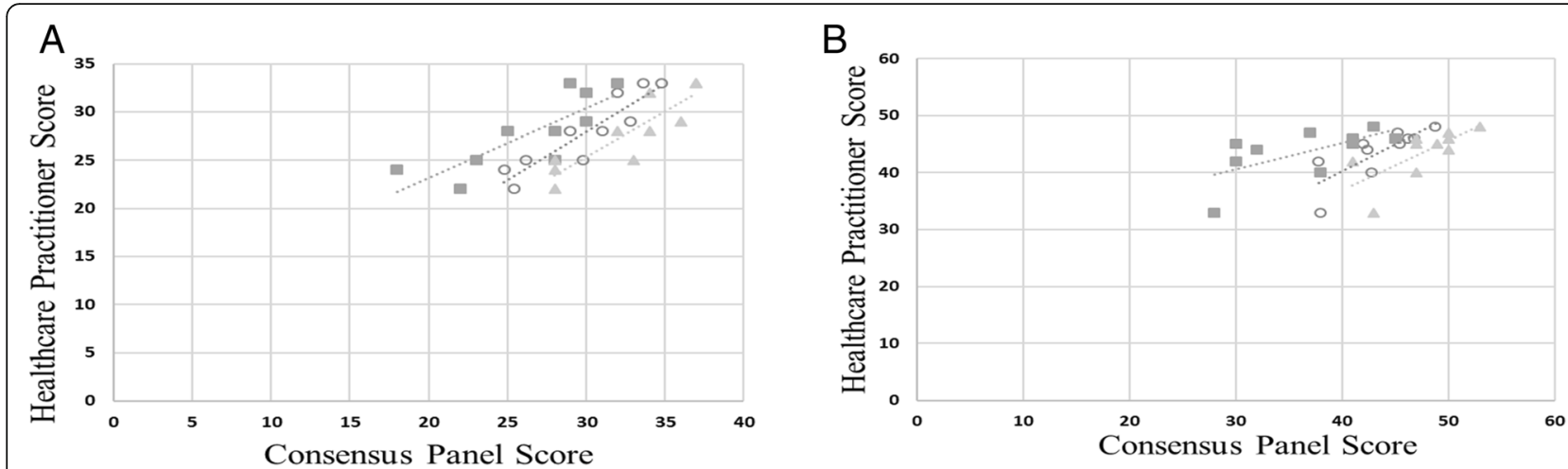

Fig. 2 Criterion validity as measured through Spearman's correlation analysis of mean, minimum and maximum scores of individual healthcare practitioners (HCP) and consensus scores of healthcare professionals for physical function (PF) (a) and safe use of the equipment (EQ) (b) domains of the SUMAC

Our criterion validity analysis demonstrated that an observational gait assessment with the POMA gait subscale was correlated with the PF score of the SUMAC, but not with the EQ score. This relationship is consistent with our hypothesis because physical strength, balance and quality of gait are independent of unsafe techniques for use of the equipment. A study by Robinovitch et al. [37] found that $74 \%$ of long-term care residents were classified as habitual users of assistive devices and that a quarter of falls occurred while using an assistive device. Specifically, there was an increased risk of falls when transferring to use the mobility aid and the researchers identified safety concerns of people not appropriately using the prescribed device [37]. Our assessment tool includes the assessment of transitions between sitting and standing, and the challenges identified by Lindemann et al. [19] of manoeuvring the walker when navigating doors that open away and towards the user of the device.

Balance decreases with progression of cognitive impairment in dementia [38]. Postural control is affected in many ways by dementia; in particular, there are visual perceptual changes, slower sensory processing, reduced motor responses and increased attentional demands that impact static and dynamic balance [39]. A person with dementia commencing use of a 4-wheeled walker after diagnosis presents unique challenges for rehabilitation professionals. It is important to recognize that people with dementia have a preserved capacity for learning [40]. Training protocols that use procedural (implicit) learning optimize acquisition and retention of new skills [39]. There is some evidence to suggest that these methods are clinically useful in assisting those with dementia to learn and retain the skills for proper use of their walker [41]. Reinforcement of instructions by all healthcare members facilitates the process of procedural learning. The SUMAC scale presents a standardized list, in sequential order, of activities to be completed within the nine tasks. The tool has the potential to facilitate uniform expectations of performance with the equipment and education with appropriate reinforcement for people using a 4-wheeled walker.

There are several strengths of the study that we would like to highlight. Input was provided by a range of clinicians, healthcare professionals, and academics with expertise in geriatrics and dementia. We have provided a comprehensive evaluation of validity and psychometric properties of reliability. Additionally, the use of functional tasks while using the 4-wheeled walker is an advantage to people with dementia. This is the first tool to allow clinicians to objectively quantify, standardize, and track progress of an individual's ability to safely use a mobility aid. There are some limitations that should be noted. The SUMAC was created solely for the assessment of 4-wheeled walker use and thus the tool is not applicable to canes or crutches. In our reliability phase of our study, inclusion criteria of participants was restricted to those with mild to moderate disease severity. Future research should examine the psychometric properties of the SUMAC in people with more advanced disease severity as it is not expected that performance of the tool will be comparable in severe disease. While we had an appropriate sample size to achieve power for the analysis, further evaluation should be conducted with a larger sample using in-person evaluation of performance.

\section{Conclusion}

The focus groups and research team created an assessment tool, the SUMAC, comprising nine tasks and components within each task to evaluate physical function and safe use of a 4-wheeled walker by people with dementia. The SUMAC demonstrated good to excellent inter-rater and test retest reliability, as well as strong support for construct and criterion validity. Therefore, the SUMAC shows promise as a new tool to assess 
function and mobility aid safety in a population in which falls and mobility aid use are prevalent. Future research should examine the psychometric properties of the SUMAC in people with more advanced disease severity and evaluate its use in conjunction with interventions to improve gait in people with dementia using a 4-wheeled walker.

\section{Supplementary Information}

The online version contains supplementary material available at https://doi. org/10.1186/s12877-020-01865-5.

Additional file 1. Safe Use of Mobility Aids Checklist (SUMAC)

\section{Abbreviations}

HCP: Health care professional; ICC: Intra-class correlation coefficient; MDC 95 : Minimal Detectable Difference; POMA: Performance-Oriented Mobility Assessment tool; SEM: Standard error of measurement; SUMAC: Safe Use of Mobility Aids Checklist tool; SUMAC-PF: Physical Function component of the Safe Use of Mobility Aids Checklist; SUMAC-EQ: Equipment use component of the Safe Use of Mobility Aids Checklist

\section{Acknowledgements}

The authors would like to thank Karen Johnson, Director of McCormick Dementia Services; Steve Crawford, CEO, McCormick Care Group; Catherine Blake, McCormick Dementia Research and the staff and clients at the McCormick Dementia Services day program for their hospitality, assistance in organizing this project and participation in the data collection process. Additionally, we would like to thank all the healthcare professionals who were involved in each of the stages of the development and testing of the SUMAC.

\section{Authors' contributions}

SWH: Funding, study concept and design, item generation for Phase 1, focus groups data collection in Phase 1 (scale development), statistical analysis, interpretation of data, drafting of the manuscript and revising the manuscript for important intellectual content. AD: Item generation, data collection for Phase 1 (scale development) and revising the manuscript for important intellectual content. HO: Data collection for Phase 2 (reliability and validity), drafting of manuscript and revising the manuscript for important intellectual content. EM: Data collection for Phase 2 (reliability and validity), statistical analysis, interpretation of data, drafting of the manuscript and revising the manuscript for important intellectual content. JH: Funding, study design, item generation for Phase 1, interpretation of data for Phase 1 and 2 , and revising the manuscript for important intellectual content. All authors have read and approved the manuscript.

\section{Funding}

This study was supported with funding from the Faculty Research Development Fund from the Faculty of Health Sciences at the University of Western Ontario and the Ontario Neurotrauma Foundation (2019-PREV-FALL1070). The funder had no role in the design of the study, data collection, analysis, interpretation of data or in writing the manuscript.

\section{Availability of data and materials}

The datasets used and/or analyzed during the current study are available from the corresponding author on reasonable request.

\section{Ethics approval and consent to participate}

The project was conducted in accordance to the Declaration of Helsinki and was approved by the University of Western Ontario Research Ethics Board for Health Sciences Research Involving Human Subjects. For the participants with dementia, informed written consent was provided by either the participants or their substitute decision makers, who provided informed consent on their behalf, and then the participants provided assent to participate in the study. All healthcare professionals provided written informed consent prior to the start of data collection.

\section{Consent for publication}

Not applicable.

\section{Competing interests}

The authors declare that they have no competing interests.

\section{Author details}

${ }^{1}$ School of Physical Therapy, University of Western Ontario, Room 1588, Elborn College, London, ON N6G 1H1, Canada. ${ }^{2}$ Faculty of Biological Sciences, Sport and Exercise Science, University of Leeds, Leeds, England. ${ }^{3}$ Faculty of Health and Rehabilitation Sciences, University of Western Ontario, London, Ontario, Canada. ${ }^{4}$ School of Occupational Therapy, University of Western Ontario, London, Ontario, Canada.

Received: 22 January 2020 Accepted: 3 November 2020

Published online: 11 November 2020

\section{References}

1. Tinetti ME, Speechley M, Ginter SF. Risk factors for falls among elderly persons living in the community. N Engl J Med. 1988;319:1701-7.

2. Asada T, Kariya T, Kinoshita T, Asaka A, Morikawa S, Yoshioka M, et al. Predictors of fall-related injuries among community-dwelling elderly people with dementia. Age Ageing. 1996;25:22-8 http://www.ncbi.nlm.nih.gov/ pubmed/8670525

3. Ungar A, Mussi C, Ceccofiglio A, Bellelli G, Nicosia F, Bo M, et al. Etiology of syncope and unexplained falls in elderly adults with dementia: syncope and dementia (SYD) study. J Am Geriatr Soc. 2016;64:1567-73.

4. Fernando E, Fraser M, Hendriksen J, Kim CH, Muir-Hunter SW. Risk factors associated with falls in older adults with dementia: a systematic review. Physiother Can. 2017:69:161-70.

5. Wittwer JE, Webster KE, Menz HB. A longitudinal study of measures of walking in people with Alzheimer's disease. Gait Posture. 2010;32:113-7. https://doi.org/10.1016/j.gaitpost.2010.04.001.

6. Suttanon P, Hill KD, Said CM, Dodd KJ. A longitudinal study of change in falls risk and balance and mobility in healthy older people and people with Alzheimer disease. Am J Phys Med Rehabil. 2013;92:676-85. https://doi.org/ 10.1097/PHM.0b013e318278dcb3.

7. Dolatabadi E, Van Ooteghem K, Taati B, laboni A. Quantitative mobility assessment for fall risk prediction in dementia: a systematic review. Dement Geriatr Cogn Disord. 2018:45:353-67.

8. Bateni H, Maki BE. Assistive devices for balance and mobility: benefits, demands, and adverse consequences. Arch Phys Med Rehabil. 2005;86:13445

9. Clarke P, Chan P, Santaguida PL, Colantonio A. The use of mobility devices among institutionalized older adults. J Aging Health. 2009;21:611-26.

10. Härdi I, Bridenbaugh SA, Gschwind YJ, Kressig RW. The effect of three different types of walking aids on spatiotemporal gait parameters in community-dwelling older adults. Aging Clin Exp Res. 2014;26:221-8.

11. Resnik L, Allen $S$, Isenstadt D, Wasserman M, lezzoni L. Perspectives on mobility aid use in a diverse population of seniors: implications for intervention. Disabil Heal J. 2009;2:77-85.

12. Rubenstein $L Z$, Josephson $K$, Robbins A. Falls in the nursing home. Ann Intern Med. 1994;121:442-51.

13. Cameron L, Dyer S, Panagoda C, Murray G, Hill KD, Cumming RG, et al. Interventions for preventing falls in older people in care facilities and hospitals. Cochrane Database Syst Rev. 2018;12:CD005465. https://doi.org/ 10.1002/14651858.CD005465.pub4.www.cochranelibrary.com

14. Hunter SW, Divine A, Omana H, Wittich W, Hill KD, Johnson AM, et al. Effect of learning to use a mobility aid on gait and cognitive demands in people with mild to moderate Alzheimer's disease: part I - cane. J Alzheimers Dis. 2019;71:S105-s114.

15. Hunter SW, Divine A, Omana H, Wittich W, Hill KD, Johnson AM, et al. Effect of learning to use a mobility aid on gait and cognitive demands in people with mild to moderate Alzheimer's disease: part II - 4-wheeled walker. Alzheimers Dis. 2019:71:S115-24.

16. Muir-Hunter S, Montero-Odasso M, Montero Odasso M. The attentional demands of ambulating with an assistive device in older adults with Alzheimer's disease. Gait Posture. 2017;54:202-8.

17. Liu H. Assessment of rolling walkers used by older adults in senior-living communities. Geriatr Gerontol Int. 2009;9:124-30. 
18. Liu H(H), Eaves J, Wang W, Womack J, Bullock P. Assessment of canes used by older adults in senior living communities. Arch Gerontol Geriatr. 2011;52: 299-303. https://doi.org/10.1016/j.archger.2010.04.003.

19. Lindemann U, Schwenk M, Klenk J, Kessler M, Weyrich M, Kurz F, et al. Problems of older persons using a wheeled walker. Aging Clin Exp Res. 2016:28:215-20

20. Hunter SW, Meyer C, Divine A, Hill KD, Johnson A, Wittich W, et al. The experiences of people with Alzheimer's dementia and their caregivers in acquiring and using a mobility aid_a qualitative study. Disabil Rehabil. 2020;0:1-8. https://doi.org/10.1080/09638288.2020.1741700.

21. Lam FM, Huang MZ, Liao LR, Chung RC, Kwok TC, Pang MY. Physical exercise improves strength, balance, mobility, and endurance in people with cognitive impairment and dementia: a systematic review. J Physiother. 2018;64:4-15. https://doi.org/10.1016/j.jphys.2017.12.001.

22. Hunter SW, Omana H, Madou E, Wittich W, Hill KD, Johnson AM, et al. Effect of dual-tasking on walking and cognitive demands in adults with Alzheimer's dementia experienced in using a 4-wheeled walker. Gait Posture. 2020;77:164-70.

23. Leary P. Walking sticks used by elderly patients. Br Med J. 1982;285:58,

24. Panel for Prevention of Falls in Older Adults, American Geriatrics Society, Society BG. Summary of the updated American Geriatrics Society/British Geriatrics Society clinical practice guideline for prevention of falls in older persons. J Am Geriatr Soc. 2011;59:148-57. https://doi.org/10.1111/j.15325415.2010.03234.x

25. Albert MS, DeKosky ST, Dickson D, Dubois B, Feldman HH, Fox NC, et al. The diagnosis of mild cognitive impairment due to Alzheimer's disease: recommendations from the National Institute on Aging-Alzheimer's Association workgroups on. Alzheimers Dement. 2011;7:270-9. https://doi. org/10.1016/j.jalz.2011.03.008

26. Lawton MP, Brody EM. Assessment of older people: self-maintaining and instrumental activities of daily living. Gerontologist. 1969;9(3_Part_1):179-86.

27. Delbaere K, Close JCT, Taylor M, Wesson J, Lord SR. Validation of the iconographical falls efficacy scale in cognitively impaired older people. J Gerontol Ser A Biol Sci Med Sci. 2013;68:1098-102.

28. Faber MJ, Bosscher RJ, van Wieringen PC. Clinimetric properties of the performance-oriented mobility assessment. Phys Ther. 2006;86:944-54

29. Sterke CS, Huisman SL, van Beeck EF, Looman CWN, Van Der Cammen TJM. Is the Tinetti performance oriented mobility assessment (POMA) a feasible and valid predictor of short-term fall risk in nursing home residents with dementia? Int Psychogeriatr. 2010;22:254-63.

30. Walter SD, Eliasziw M, Donner A. Sample size and optimal designs for reliability studies. Stat Med. 1998;17:101-10.

31. Streiner D, Norman G. Health measurement scales: a practical guide to their development and use. New York: Oxfor University Press; 2003.

32. Bruton A, Conway J, Holgate S. Reliability: what is it and how is it measured? Physiotherapy. 2000;86:94-9.

33. Cohen J. Statistical power analysis for the behavioral sciences; 1988.

34. Gell NM, Wallace RB, LaCroix AZ, Mroz TM, Patel KV. Mobility device use in older adults and incidence of falls and worry about falling: findings from the 2011-2012 National Health and aging trends study. J Am Geriatr Soc. 2015;63:853-9.

35. Stevens JA, Thomas K, Teh L, Greenspan Al. Unintentional fall injuries associated with walkers and canes in older adults treated in U.S. emergency departments. J Am Geriatr Soc. 2009;57:1464-9.

36. van Riel KMM, Hartholt KA, Panneman MJM, Patka P, van Beeck EF, van der Cammen TJM. Four-wheeled walker related injuries in older adults in the Netherlands. Inj Prev. 2014;20:11-5.

37. Robinovitch SN, Feldman F, Yang Y, Schonnop R, Leung PM, Sarraf T, et al. Video capture of the circumstances of falls in elderly people residing in long-term care: an observational study. Lancet. 2013;381:47-54. https://doi. org/10.1016/S0140-6736(12)61263-X.

38. Tangen GG, Engedal K, Bergland A, Moger TA, Mengshoel AM. Relationships between balance and cognition in patients with subjective cognitive impairment, mild cognitive impairment, and Alzheimer disease. Phys Ther. 2014;94:1123-34.

39. Ries JD. Rehabilitation for individuals with dementia: facilitating success. Curr Geriatr Rep. 2018;7:59-70.

40. Zanetti O, Zanieri G, Di Giovanni G, De Vreese LP, Pezzini A, Metitieri T. Effectiveness of procedural memory stimulation in mild Alzheimer's disease patients: a controlled study. Neuropsychol Rehabil. 2001;11:263-72.
41. Creighton AAS, TE Davison TTE, van der Ploeg ES, Camp CCJ, O'Connor D, O'Connor DW. Using spaced retrieval training to teach people with dementia to independently use their walking aids: two case studies. Clin Gerontol. 2015;38:170-8. https://doi.org/10.1080/07317115.2014.988899.

\section{Publisher's Note}

Springer Nature remains neutral with regard to jurisdictional claims in published maps and institutional affiliations.
Ready to submit your research? Choose BMC and benefit from:

- fast, convenient online submission

- thorough peer review by experienced researchers in your field

- rapid publication on acceptance

- support for research data, including large and complex data types

- gold Open Access which fosters wider collaboration and increased citations

- maximum visibility for your research: over $100 \mathrm{M}$ website views per year

At BMC, research is always in progress.

Learn more biomedcentral.com/submissions 